\title{
Continuous respiratory support in quadriplegic children by bilateral phrenic nerve stimulation
}

\author{
H GARRIDO, J MAZAIRA, P GUTIERREZ, E GONZALEZ, J RIVAS, J MADRAZO \\ From the Departamento de Cirugia de la Facultad de Medicina de Cadiz; Servicio de Medicina Interna, Hospital \\ de Paraplegicos, Toledo; and Unidad de Cuidados Intensivos, Residencia Sanitaria "Virgen del Rocio," Seville, \\ Spain
}

ABSTRACT Three children, aged 6-10 years, in whom cervical cord injury at the C1-C2 level resulted in apnoea had bilateral implantation of diaphragm pacemakers. With periods of gradual conditioning of the diaphragm muscle to low frequency stimulation and slow respiratory rates they adapted to continuous ventilatory support by simultaneous stimulation of both hemidiaphragms without evidence of fatigue, so far for periods of 23-47 months.

Continuous support of ventilation by electrical stimulation of the phrenic nerves was first reported in an adult quadriplegic patient with respiratory muscle paralysis by Glenn et al in $1972 .^{1}$ Adequate ventilation was obtained by electrical stimulation of each hemidiaphragm alternately for 12 hours. More prolonged stimulation of the diaphragm resulted in fatigue. $^{2}$ Continuous ventilation by diaphragm pacing in infants and children has not hitherto been possible as bilateral simultaneous pacing of both hemidiaphragms is required to provide adequate ventilation. $^{3}$

Recent laboratory studies to determine the optimal settings for diaphragmatic pacing have shown that continuous bilateral simultaneous pacing is possible without injury to the phrenic nerve or diaphragm muscle if wide pulse interval stimulation of the phrenic nerve at a slow pulse train repetition (respiratory) rate is used. ${ }^{4}$ This technique has been applied to older children and adult quadriplegic patients with diaphragmatic paralysis and has provided continuous ventilation without evidence of diaphragm fatigue over extended periods. ${ }^{56}$

The present report describes the results in three quadriplegic children with paralysis of the diaphragm who had diaphragm pacemakers implanted and were able to adapt, through gradual conditioning to pacing, to continuous ventilatory support by simultaneous stimulation of both phrenic nerves, which they have had for from 23 to 47 months.

Address for reprint requests: Dr H Garrido, Departamento de Cirugia de la Facultad de Medicina de Cadiz, Cadiz, Spain.

Accepted 22 December 1986

\section{Patients and methods}

Three quadriplegic children, one boy and two girls (patients 1, 2, and 3) aged 10, six and six years respectively, suffered from traumatic lesions of the cervical cord at the level of $\mathrm{C} 1-\mathrm{C} 2$ as a result of motor vehicle accidents. The time between injury and pacemaker implantation was one year in patient 1 and 10 and nine months respectively in patients 2 and 3 . During this time they were mechanically ventilated continuously via a tracheostomy.

Preoperative studies consisted of fluoroscopic confirmation of immobility of the diaphragm and determination of viability of the phrenic nerves through transcutaneous stimulation of the phrenic nerves in the neck. ${ }^{78}$ The operative techniques for implantation of the diaphragm pacemaker have been described in detail by Glenn et al. ${ }^{2}$ The phrenic nerve was exposed through a thoracotomy in the second intercostal space anteriorly. A monopolar electrode was inserted behind the phrenic nerve in the mediastinal portion midway between the base of the heart and the apex of the thoracic cavity, where it was fixed in place with prolene sutures. The radio receiver was implanted subcutaneously through an incision in the anterolateral axillary line at the costal margin in a pocket developed between the costal margin and the inframammary fold. The pocket was about $10 \mathrm{~cm}$ deep and extended laterally and medially for a distance of some $3-4 \mathrm{~cm}$ to accommodate the electronic parts (receiver, anode electrode plate and electrode receiver connectors). A receiver electrode assembly was implanted on the right and left sides, at two separate operations 15 days apart.

Two weeks after the second operation simultaneous pacing of both hemidiaphragms was initiated 
in patients 1 and 2 . In patient 3 it was necessary to postpone pacing for 80 days on the left side because of temporary paralysis of the phrenic nerve. Successful pacing of the left hemidiaphragm was instituted after recovery of phrenic nerve function (fig 1). Avery S242 transmitters (Avery Laboratories, Farmingdale, New York, 11/35) were used in each case.

Before the pacing schedule was started the threshold of the diaphragm muscle to stimulation and the current amplitude required for maximal descent of the diaphragm were determined at fluoroscopy and recorded for both hemidiaphragms separately. These studies were repeated at intervals of about one month for the first six months postoperatively and appropriate adjustments were made in the stimulation specifications. Thereafter these studies were repeated about every six months.

The threshold of excitation is defined as the current required to produce minimal contraction of the hemidiaphragm with electrical stimulation of the phrenic nerve by the pacemaker. Maximal current amplitudes are defined as the current required for maximal descent of the hemidiaphragm in response to electrical stimulation of the phrenic nerve.

\section{CONDITIONING OF THE DIAPHRAGM}

Once the pacing characteristics were established for each hemidiaphragm, bilateral simultaneous diaphragm pacing was initiated, with the mechanical ventilator disconnected temporarily, for 5-10 minutes each hour during waking hours at a pulse interval of 90 milliseconds (pulse frequency $11 \mathrm{~Hz}$ ) and a respiratory rate of 10-15 per minute. The amplitude of the electrical current applied was just sufficient to obtain the maximal tidal volume, which usually corresponded to the maximal current amplitude as assessed by fluoroscopy. Tidal and minute volumes were measured by a Bourns Ventilation Monitor model LS75 (Bear Medical Systems, Riverside, California 92503) at the beginning and end of each pacing period; the arterial blood gas tensions were determined periodically to confirm the adequacy of ventilation.

The time given to pacing was increased every two weeks until pacing periods of $\mathbf{3 0}$ minutes an hour dur- ing waking hours were reached. Further increments in the pacing period were then made, interspersed with equal periods of rest on a mechanical respirator, until 12 hours of continuous pacing was achieved without evidence of fatigue. If the minute volume decreased by more than $25 \%$, the next pacing period remained the same or was shortened. The periods of rest were subsequently shortened until full time pacing was achieved. The respiratory rate was reduced periodically until, when conditioning was completed four to six months later, it reached eight respirations a minute, the lowest rate which would provide the patient's ventilatory requirements.

The pulse interval was increased gradually until it reached $120 \mathrm{~ms}$.

During the period of conditioning the following studies were carried out at intervals of 15 days:

(1) determination of threshold current level and maximum amplitude, and

(2) measurement of tidal and minute volumes with pacing at varying pulse intervals $(40,60,90,110$, $120 \mathrm{~ms}$ ) by spirometry.

The current peak and threshold applied to the phrenic nerves were adjusted by dial calibration of the transmitter.

Each of the children achieved full time ventilatory support by bilateral simultaneous diaphragm pacing. When full time pacing had been established the tracheostomy tube was replaced by a short straight teflon tube and obturator, extending from the skin to just inside the tracheal lumen, where it was held in place by a small flange, sized for each patient individually. The obturator was removed from the tube during sleep to assure a patent upper airway.

\section{Results}

The preoperative values of phrenic nerve conduction time and muscle action potentials are shown in table 1 .

The periods required to condition the diaphragm in the three patients were 5,7 , and 11 months respectively. These periods are longer than in adult patients, but were necessary to avoid fatigue of the

Table 1 Phrenic nerve conduction time and diaphragm muscle action potential*

\begin{tabular}{|c|c|c|c|c|c|}
\hline \multirow[b]{2}{*}{ Case No } & \multirow[b]{2}{*}{ Age (y) } & \multicolumn{2}{|c|}{ Conduction time (ms) } & \multicolumn{2}{|c|}{ Muscle potential ( $\mu v)$} \\
\hline & & Right & Left & Right & Left \\
\hline $\begin{array}{l}1 \\
2 \\
3\end{array}$ & $\begin{array}{r}10 \\
6 \\
6\end{array}$ & $\begin{array}{l}8 \\
6 \cdot 5 \\
4 \cdot 1\end{array}$ & $\begin{array}{l}8 \\
7 \cdot 5 \\
4.8\end{array}$ & $\begin{array}{l}500 \\
750 \\
770\end{array}$ & $\begin{array}{l}500 \\
250 \\
770\end{array}$ \\
\hline
\end{tabular}

* Normal conduction time is less than 12 milliseconds; the muscle action potential is variable and is normally $150-750 \mu v$ when measured by surface electrodes. 


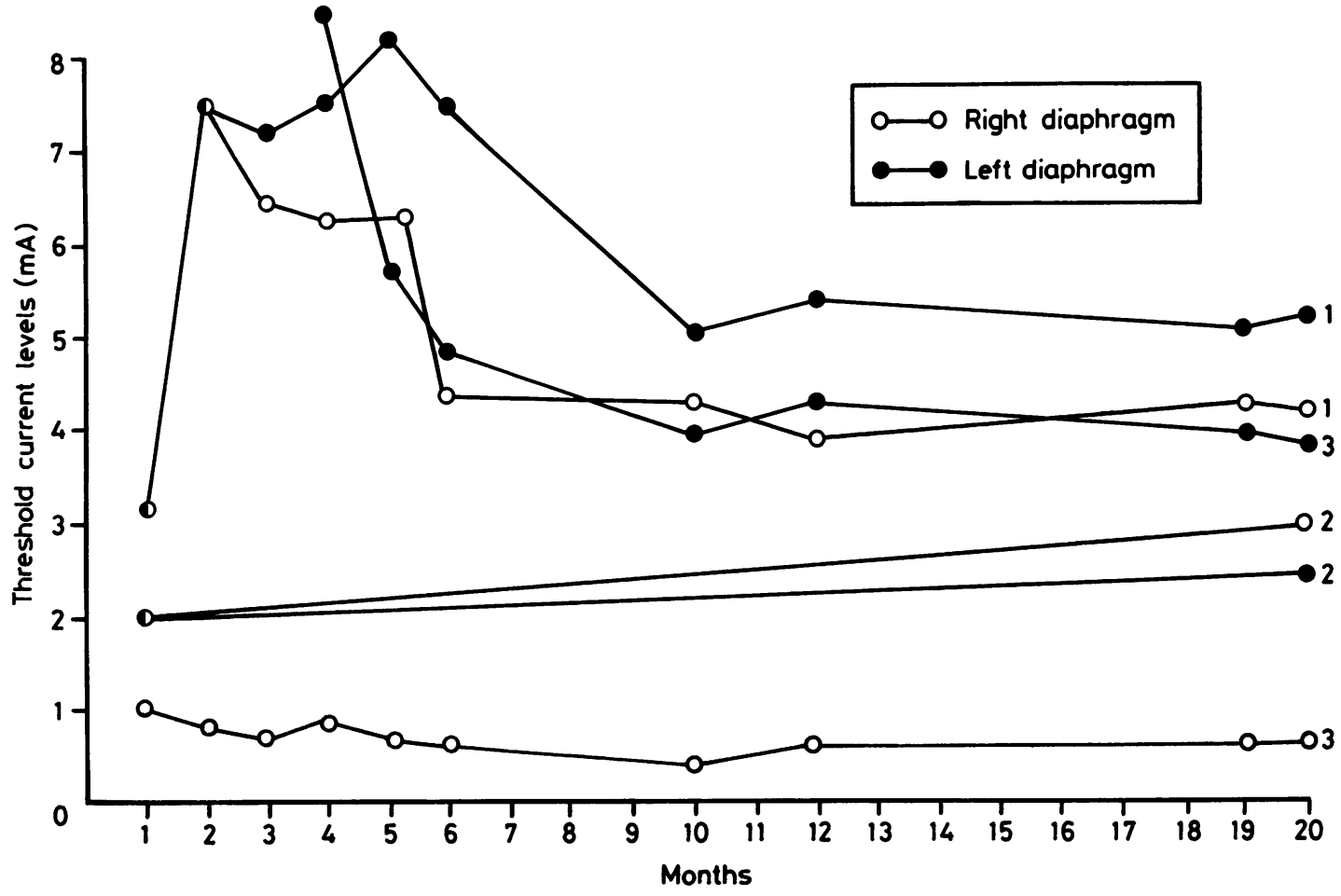

Fig 1 Changes in threshold levels in the three patients during conditioning of the diaphragm. The threshold of excitation is defined as the current required to produce minimal contraction of the hemidiaphragm with electrical stimulation of the phrenic nerve by the pacemaker.

diaphragm; the longer period required for patient 3 was due to temporary loss of function of the left phrenic nerve after application of the neural electrode.

The threshold to stimulation was variable in patient 1 , increasing substantially during the first month after pacing had begun and decreasing thereafter to $3 \mathrm{~mA}$ on the right side and to $7 \mathrm{~mA}$ on the left. In patient 2 the threshold varied only slightly-from 2 to $2.5 \mathrm{~mA}$. In patient 3 the threshold was temporarily lost; it was $9 \mathrm{~mA}$ when recovery of the nerve initially occurred but then decreased progressively until it stabilised at 3-4 mA (fig 1).

The results of paced ventilation at the end of the conditioning period are summarised in table 2 .

Spirometric measurements obtained during unilateral pacing at wide and narrow pulse intervals (from 120 to $40 \mathrm{~ms}$ ) showed an increase throughout the period of conditioning (fig 2).

The patients have been followed for 47,26 , and 23 months from the time pacing was begun, with no obvious signs of fatigue of the diaphragm. Patients 1 and 3 are at home and patient 2 lives in a rehabilitation centre.

Table 2 Results of paced ventilation at the end of the conditioning period: permanent ventilatory support with bilateral phrenic nerve stimulation

\begin{tabular}{|c|c|c|c|c|c|c|c|c|c|c|}
\hline \multirow[b]{2}{*}{$\begin{array}{l}\text { Patient } \\
\text { No }\end{array}$} & \multirow[b]{2}{*}{$\begin{array}{l}\text { Weight } \\
(\mathbf{k g})\end{array}$} & \multirow{2}{*}{$\begin{array}{l}\text { Pulse } \\
\text { interval } \\
\text { (ms) }\end{array}$} & \multicolumn{2}{|c|}{ Amplitude (mA) } & \multirow[b]{2}{*}{$\begin{array}{l}\text { Respiratory } \\
\text { rate }\left(\min ^{-1}\right)\end{array}$} & \multirow[b]{2}{*}{$\begin{array}{l}\text { Tidal volume } \\
(\mathrm{ml})\end{array}$} & \multicolumn{4}{|c|}{ Arterial blood gases } \\
\hline & & & Left & Right & & & $p H$ & $\begin{array}{l}\mathrm{PaCO}_{2} \\
(\mathrm{~mm} \mathrm{Hg})\end{array}$ & $\begin{array}{l}\mathrm{PaO}_{2} \\
(\mathrm{~mm} \mathrm{Hg})\end{array}$ & $\begin{array}{l}\mathrm{SaO}_{2} \\
(\%)\end{array}$ \\
\hline $\begin{array}{l}1 \\
2 \\
3\end{array}$ & $\begin{array}{l}32 \\
28 \\
22\end{array}$ & $\begin{array}{l}120 \\
120 \\
120\end{array}$ & $\begin{array}{l}7 \\
3 \cdot 5 \\
2 \cdot 5\end{array}$ & $\begin{array}{l}3 \\
1 \cdot 5 \\
2 \cdot 5\end{array}$ & $\begin{array}{l}8 \\
7 \\
8\end{array}$ & $\begin{array}{l}400 \\
500 \\
375\end{array}$ & $\begin{array}{l}7 \cdot 43 \\
7 \cdot 36 \\
7 \cdot 40\end{array}$ & $\begin{array}{l}36 \\
38 \\
31\end{array}$ & $\begin{array}{l}97 \\
97 \\
97\end{array}$ & $\begin{array}{l}96 \\
98 \\
98\end{array}$ \\
\hline
\end{tabular}

$\mathrm{PaCO}_{2}, \mathrm{PaO}_{2}$-arterial carbon dioxide and oxygen tension; $\mathrm{SaO}_{2}-$ oxygen saturation.

Conversion: Traditional to SI units-Blood gases: $1 \mathrm{~mm} \mathrm{Hg} \approx 0.133 \mathrm{kPa}$. 


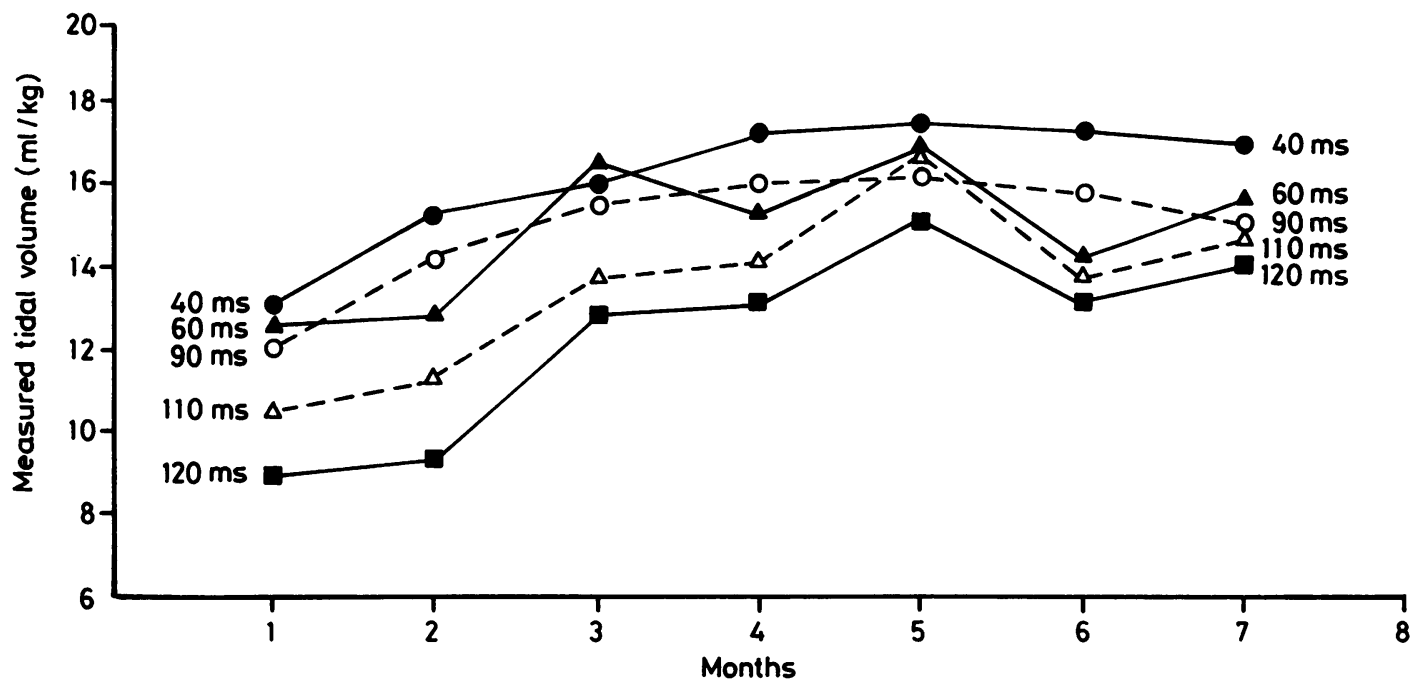

Fig 2 Mean tidal volume of the three patients during unilateral stimulation, measured at various pulse intervals to show the increase during the conditioning period.

\section{Discussion}

Diaphragm pacing has been successful for long periods in several infants and small children, ${ }^{910}$ but continuous bilateral pacing in an infant, without conditioning of the diaphragm, was only temporarily successful ${ }^{11}$ and the continuous application of this method of ventilatory support in young children has not been reported. The group of patients reported by Glenn $e \mathrm{al}^{5}$ included a boy of seven years in whom bilateral simultaneous pacing using low frequency stimulation at a slow respiratory rate was applied successfully for a considerable time. The three children in our series, all quadriplegic with respiratory paralysis, also achieved full time ventilatory support by bilateral simultaneous continuous diaphragm pacing after conditioning of the diaphragm. Whether this method of continuous pacing can be supplied successfully to the infant and younger child has not been determined.

Adequacy of ventilation in these patients during pacing was determined by frequency monitoring of tidal and minute volumes and by periodic arterial blood gas measurements. Arterial oxygen saturation and end tidal carbon dioxide may also be used to monitor adequacy of ventilation in patients undergoing pacing (WWL Glenn, personal communication).

The rationale of continuous bilateral pacing of the diaphragm using a slow respiratory rate and low frequency stimulation has been summarised by Glenn et al. ${ }^{5}$ In brief, the success of this technique of diaphragm pacing without fatigue is attributed to several factors. Firstly, the lungs are ventilated more efficiently when both hemidiaphragms are stimulated simultaneously than when alternate hemidiaphragm pacing is used. Secondly, this method of stimulation does not result in pathological changes in the muscle or nerves. Thirdly, low frequency stimulation of the muscle converts the normal mixture of slow twitch and fast twitch muscle fibres found in the human diaphragm to a uniform population of fatigue resistant slow twitch fibres with type 1 characteristics. Finally, when low frequency stimulation at a slow respiratory rate is used, both the force and the time of muscle contraction are reduced, thereby preventing fatigue.

A major advantage of full time ventilation by diaphragm pacing in children is increased mobility, as the child is no longer tethered to a mechanical respirator. Thus the quadriplegic child can participate in family life, with the possibility of eventually pursuing an independent career.

This work was supported in part by the Comision Asesera de Investigacion Cientifica y Tecnica.

\section{References}

1 Glenn WWL, Holcomb WG, McLaughlin AJ, O'Hare JM, Hogan JF, Yasuda R. Total ventilation support in a quadriplegic patient with radiofrequency electrophrenic respiration. $N$ Engl J Med 1972;286:513-6.

2 Glenn WWL, Hogan JF, Phelps ML. Ventilatory sup- $\varrho$ port of the quadriplegic patient with respiratory paral- $O$ ysis by diaphragm pacing. Surg Clin North Am 1980;60:1055-78. 
3 Hunt CE, Metalon SV, Thompson TR, Demuth S, Loew JM, Mielin H, Mastri A, Burke B. Central hypoventilation syndrome. Experience with bilateral phrenic nerve pacing in 3 neonates. Am Rev Respir Dis 1978;118:23-6.

4 Oda T, Glenn WWL, Fukuda Y, Hogan JF, Gorfien J. Evaluation of electrical parameters for diaphragm pacing: an experimental study. $J$ Surg Res 1981;30:142-53.

5 Glenn WWL, Hogan KF, Loke JSO, Ciesielski TE, Phelps ML, Rowedder R. Ventilatory support by pacing of the conditioned diaphragm in quadriplegia. $N$ Engl J Med 1984;310:1150-5.

$6 \mathrm{Kim} \mathrm{JH}$, Manuelidis EE, Glenn WWL, Kaneyuky T. Diaphragm pacing: histopathologic changes in the phrenic nerve following long-term electrical stimu- lation. J Thorac Cardiovas Surg 1976;22:602-8.

7 Newson Davis J. Phrenic nerve conduction in man. J Neurol Neurosurg Psychiat 1967;30:420-6.

8 Shaw RK, Glenn WWL, Hogan JF, Phelps ML. Electrophysiological evaluation of phrenic nerve function in candidates for diaphragm pacing. $J$ Neurosurg 1980;53:345-54.

9 Glenn WWL. Pacing the diaphragm in infants. Ann Thorac Surg 1985;40:319-20.

10 Ilbawi MN, Idriss FS, Hunt CE, Brouillette RT, DeLeon SY. Diaphragmatic pacing in infants: techniques and results. Ann Thorac Surg 1985;40:323-9.

11 Radecki LL, Tomatis LA. Continuous bilateral electrophrenic pacing in an infant total diaphragmatic paralysis. J Pediat 1976;88:969-71. 